\title{
Association between Metabolic Syndrome and Erythrocyte Fatty Acid Profile in Mexican Adolescents: A Trans Fatty Acid Approach
}

\author{
Martínez-Razo Gabriel, Martínez-Basila Azucena, Salas-Fernández Alejandra, \\ Maldonado-Hernández Jorge*
}

Mass Spectrometry Laboratory, Research Unit in Medical Nutrition, Pediatric Hospital, National Medical Center 21st Century, Mexican Institute of Social Security, Mexico City, Mexico.

Email: ${ }^{*}$ jormh@yahoo.com.mx

Received May $16^{\text {th }}, 2013$; revised June $16^{\text {th }}, 2013$; accepted June $24^{\text {th }}, 2013$

Copyright (C) 2013 Martínez-Razo Gabriel et al. This is an open access article distributed under the Creative Commons Attribution License, which permits unrestricted use, distribution, and reproduction in any medium, provided the original work is properly cited.

\begin{abstract}
The type of fat consumed in the Mexican diet could predispose to the development of Metabolic Syndrome (MS) which has been associated with an increased risk to develop cardiovascular disease and type 2 diabetes mellitus. Our study included adolescents between 12 and 16 years of age, divided in two groups: Control Group $(\mathrm{n}=31)$ and MS Group (n $=44$ ). Waist circumference, blood pressure, fasting glucose, triglycerides, and HDL-cholesterol were determined. Erythrocytes' fatty acids methyl esthers were quantified using gas chromatography with ionized flame detector. We identified 16 fatty acids (FA) with chain lengths from C12 to C24, with emphasis in four trans FA (TFA) isomers: vaccenic $(\mathrm{C} 18: \ln 7 t)$, elaidic $(\mathrm{C} 18: 1 \mathrm{n} 9 t)$, linoelaidic $(\mathrm{C} 18: 2 \mathrm{n} 6 t)$, and conjugated linoelaidic acids $(\mathrm{C} 18: 2 \mathrm{n} 7 t)$. MS Group had a less proportion of: myristic (C14), palmitoleic (C16:1), C18:1n7t, and linoleic acids (C18:2); and a higher one of $\mathrm{C} 18: 1 \mathrm{n} 9 t, \mathrm{C} 18: 2 \mathrm{n} 7 t$, and nervonic acids (C24:1) when compared to the control group. $\mathrm{C} 24: 1$ and $\mathrm{C} 18: 1 \mathrm{n} 9 t$ had a significant positive association with $\mathrm{MS}(\mathrm{OR}=14.17$ and $\mathrm{OR}=12.94$, respectively); whereas $\mathrm{C} 14(\mathrm{OR}=0.14), \mathrm{C} 18: 1 \mathrm{n} 7 t$ $(\mathrm{OR}=0.14)$, and $\mathrm{C} 18: 2(\mathrm{OR}=0.22)$ appear to have a protective effect against the disease. The proportion of specific FAs in erythrocytes' membranes differs between adolescents with MS and healthy controls; these FA not only showed a strong association with MS, but also correlated with most of its individual components. Interestingly, TFA displayed an antagonic behavior; while $\mathrm{C} 18: \ln 9 t$ had a strong association with MS, apparently $\mathrm{C} 18: \ln 7 t$ confers a protective effect; these results suggest that analyzing each TFA separately will constitute a more accurate approach to determine the role of TFAs in the pathogenesis of MS or other related metabolic disorders.
\end{abstract}

Keywords: Metabolic Syndrome; Fatty Acid Profile; Erythrocyte Membrane

\section{Introduction}

Metabolic Syndrome (MS) in children is defined as the presence of three or more of the following features: obesity, dyslipidemia (increased triglycerides, TG; and/or decreased high density lipoprotein cholesterol, HDL-C), hypertension, and/or impaired glucose metabolism [1].

The growth in obesity, which has reached alarming proportions, has contributed to increase the prevalence of MS in children [2-4]. One of the main concerns about MS in pediatric population is that after due consideration of age, puberty, growth, gender, and ethnic-specific influences; the gathering of these metabolic detriments

${ }^{*}$ Corresponding author. may predict the early onset of adulthood cardiovascular disease and type 2 diabetes mellitus [5].

It is well known that diet varies markedly across cultures, however in the last few decades, major changes concerning the quality and quantity of dietary fat have occurred worldwide, changes that may be directly related with the progression of this metabolic impairment $[6,7]$.

Both, observational studies [8] and clinical trials [9] have revealed that fatty acid (FA) composition in human tissues varies widely as a result of fat intake [10]; whereas plasma lipid profile mirrors only dietary fat, within the previous few days [11]; the measurement of FA profile in erythrocytes' membranes is a better longterm dietary fat biomarker, which also reflects endoge- 
nous FA metabolism [12] and constitutes a fair approach to FA composition in muscle cells [13].

FA profile has a marked clinical importance, because it can interfere adversely with the physicochemical properties of the cell membrane, such as protein binding affinity and eicosanoids activation and synthesis [7,14].

Although to our knowledge, there is no evidence concerning changes in the FA profile of erythrocytes' membranes in adolescents with MS, cutting-edge studies in adult population have revealed that a lower proportion of polyunsaturated and monounsaturated fatty acids (PUFA and MUFA) in erythrocytes' membranes is inversely associated with MS, while a high content in saturated fatty acids (SFAs) is positively associated [14-16].

Trans Fatty Acids (TFAs), unsaturated FA with at least one double bond in trans configuration, may also provide a good MS-risk biomarker given the fact that they relay almost exclusively on dietary intake [17-19] and are known to have adverse effects on serum lipids [20]. TFAs are mostly produced during the partial hydrogenation of vegetable oils into semisolid fats in the food industry $[8,20,21]$; however TFAs may also be formed naturally throughout the rumination process, so small amounts of TFAs are present in dairy products and meat [22]. Vaccenic acid, from which conjugated linoleic acid is formed, is the predominant trans-isomer in ruminants [17]. Recent studies in adults and in pediatric populations have shown that a high dietary intake of TFAs increases serum low-density lipoprotein cholesterol (LDL-C) and TG, and decreases serum HDL-C [20, 23-28]; besides, the human lipase enzyme is specific for cis configuration and is ineffective with trans configuration, so trans fat remains in the bloodstream for a much longer period of time [26].

In the Mexican Health and Nutrition 2006 National Survey (ENSANUT 2006), a sample of 8690 children and adolescents, underwent a food-frequency questionnaire. According to the World's Health Organization's recommendations, the data obtained from the Survey revealed that Mexican children and adolescents had an insufficient intake of PUFAs, and an excessive intake of SFAs and TFAs [29]. These findings suggest that the quality and quantity of the fat consumed in the Mexican diet could predispose youngsters to the development of metabolic disorders and cardiovascular complications in early adulthood; therefore, the aim of this study was to evaluate if the presence of MS is associated with the FA profile in erythrocytes' membranes, emphasizing TFA contribution.

\section{Methods}

The study was conducted in the Research Unit in Medical Nutrition, of the Mexican Institute of Social Security in Mexico City. The protocol was approved by the ethics committee of this institute (R-2010-3603-35). The legal guardian of all study subjects provided written informed consent, and every child gave his approval to participate in the study.

\subsection{MS Definition}

MS was defined according to the following criteria: waist circumference $(\mathrm{WC})>90^{\text {th }}$ percentile and at least three of the following; HDL-C $<50 \mathrm{mg} / \mathrm{dL}, \mathrm{TG}>110 \mathrm{mg} / \mathrm{dL}$, diastolic and/or systolic blood pressure $(\mathrm{BP})>90^{\text {th }}$ percentile adjusted by age, gender and height, and/or fasting glucose $(\mathrm{FG})>100 \mathrm{mg} / \mathrm{dL}[30,31]$.

\subsection{Clinical and Anthropometric Determinations}

WC was measured at the narrowest point between the lowest rib and the uppermost lateral border of the right iliac crest. BP was measured three times and the mean was obtained; the measurement was done in the right arm after a 5 minute rest, in a seated position. Weight was assessed with a clinical scale (Tanita, Arlington Heights, IL, TBF-300A) and height was obtained using a wall stadimeter, body mass index (BMI) was computed as [weight $(\mathrm{kg}) /$ height $\left.(\mathrm{m})^{2}\right]$.

\subsection{Biochemical Data}

After a ten hour overnight fast venous blood samples were collected $(10 \mathrm{ml}) . \mathrm{FG}, \mathrm{TG}$, and HDL-C were measured in serum by enzymatic colorimetric method (SPIN 120 automatic analyzer Shenzhen, Mindray) with commercially available kits.

\subsection{Erythrocyte Fatty Acid Profile}

Immediately after the blood sample was obtained it was centrifuged at $3000 \mathrm{rpm}$, for $10 \mathrm{~min}$ at $4^{\circ} \mathrm{C}$. Plasma was discarded and the cells were suspended in an isotonic sodium chloride solution $(0.09 \%)$. After mixing by inversion, the samples were centrifuged again, and this washing procedure was repeated twice.

FA extraction was performed according to Folch's modified method, with an isopropanol-hexane $(6.5: 4.0)$ solution. The solvent solution was added slowly to the red blood cells under vortex mixing conditions, in order to prevent the cells from caking. To separate the lipid fraction the solvent solution was evaporated under a nitrogen stream. The fatty acid portion was methylated with methanolic sodium methoxide $(0.5 \mathrm{~N})$ at $50^{\circ} \mathrm{C}$ for $20 \mathrm{~min}$ followed by an acid-catalyzed methylation with boron trifluoride in methanol $(14 \%, \mathrm{BF} 3)$ at the same time and temperature conditions. 
Erythrocytes' FA methyl esters (FAMEs) were separated and measured on a gas chromatographer (Hewlett Packard $^{\mathrm{TM}} 5890$ Series II, Palo Alto, US) coupled to an hydrogen flame detector (FID). A fused silica capillary column of $100 \mathrm{~m}, 0.25 \mathrm{~mm}$ internal diameter, and 0.20 $\mu \mathrm{m}$ film thickness (J\&W DB-225) was used. The volume of injection was of $1.0 \mu \mathrm{L}$. Helium was used as carrier gas at a flow rate of $1.2 \mathrm{ml} / \mathrm{min}$. Flame ionization temperature was fixed at $270^{\circ} \mathrm{C}$ and the injector temperature at $250^{\circ} \mathrm{C}$. The oven temperature was programmed initially at $70^{\circ} \mathrm{C}$ with a progressive rate of $30^{\circ} \mathrm{C} / \mathrm{min}$ until $175^{\circ} \mathrm{C}$, and then at $1.2^{\circ} \mathrm{C} / \mathrm{min}$ until $230^{\circ} \mathrm{C}$, once this temperature was achieved, it was held constant for $5 \mathrm{~min}$.

We identified FAs ranging from $\mathrm{C} 12$ to $\mathrm{C} 24$ chain lengths; peaks were identified by comparing their retention times against those of high purity $(<99 \%)$ standard mixtures (Sigma-Aldrich Chemie GmbH, 37 FAs mixture). In addition, TFAs: vaccenic $(\mathrm{C} 18: \ln 7 t)$, elaidic $(\mathrm{C} 18: \ln 9 t)$, linoelaidic $(\mathrm{C} 18: 2 \mathrm{n} 6 t)$, and conjugated linoleic acid $(\mathrm{C} 18: 2 \mathrm{n} 7 t)$ were verified with their high purity authentic standards (Nu-Check Prep, Inc.).

\subsection{Statistical Analysis}

Statistical analysis was performed with SPSS software (SPSS In., version 19, Chicago, IL, USA). All data are expressed as mean \pm standard deviation (SD). FAs on erythrocytes' membranes are expressed as percentage of total FAs. Differences between groups were assessed with Student's T-test and were considered significant at $\mathrm{P}<0.05$. Pearson's correlation coefficient was performed to evaluate the association between FA profile and each component of the MS. Odds ratio (OR) with a $95 \%$ confidence interval $(95 \% \mathrm{CI})$ was obtained; in order to compute OR with an appropriate cut-off point, a receiver operating characteristic (ROC) curve analysis was performed.

\section{Results}

We recruited 177 Mexican adolescents between 12 and 16 years of age. By convenience analysis we selected 75 participants ( 37 females and 38 males) in order to form two opposite study groups: 1) MS Group ( $\mathrm{n}=44)$, and 2) Control Group $(n=31)$. Adolescents who didn't met the criteria for MS, and had only 1 or 2 components of the syndrome were excluded $(\mathrm{n}=102)$ from the study protocol. As expected, significant differences in all anthropometric, biochemical, and clinical parameters were found when groups were compared. Data is summarized in Table 1.

FA profile in erythrocytes' membranes is displayed in Table 2; we can notice that MS Group had a less proportion of myristic (C14), palmitoleic (C16:1), vaccenic
Table 1. Clinical and biochemical characteristics of study subjects.

\begin{tabular}{ccc}
\hline Parameters & $\begin{array}{c}\text { Control Group } \\
(\mathrm{n}=31)\end{array}$ & $\begin{array}{c}\text { Metabolic Syndrome } \\
\text { Group }(\mathrm{n}=44)\end{array}$ \\
\hline Gender (F/M) & $18 / 13$ & $19 / 25$ \\
Age & $14.0 \pm 1.1$ & $13.3 \pm 1.4^{*}$ \\
Body mass index & $19.8 \pm 2.1$ & $29.6 \pm 4.2^{\bullet}$ \\
Waist circumference & $77.4 \pm 6.6$ & $101.4 \pm 11.6^{\circ}$ \\
Systolic blood pressure & $99.4 \pm 6.3$ & $114.3 \pm 10.2^{\bullet}$ \\
Diastolic blood pressure & $61.8 \pm 4.0$ & $71.9 \pm 9.4^{\bullet}$ \\
Fasting glucose & $82.9 \pm 7.8$ & $92.1 \pm 10.2^{\bullet}$ \\
Triglycerides & $69.4 \pm 20.8$ & $178.8 \pm 82.4^{\bullet}$ \\
HDL-cholesterol & $60.7 \pm 7.8$ & $43.2 \pm 6.0^{\bullet}$ \\
\hline
\end{tabular}

Data is expressed as mean $\pm \mathrm{SD} .{ }^{*} \mathrm{P}<0.05 ;{ }^{\circ} \mathrm{P}<0.01 ;{ }^{\bullet} \mathrm{P}<0.001$.

Table 2. Erythrocyte FA profile.

\begin{tabular}{|c|c|c|c|}
\hline Fatty acids & $\begin{array}{l}\text { Control Group } \\
\quad(\mathrm{n}=31)\end{array}$ & $\begin{array}{l}\text { MS Group } \\
(\mathrm{n}=44)\end{array}$ & $\mathrm{P}$ \\
\hline $\mathrm{C} 12: 0$ & $0.23 \pm 0.20$ & $0.15 \pm 0.14$ & 0.058 \\
\hline $\mathrm{C} 14: 0$ & $0.78 \pm 0.36$ & $0.51 \pm 0.29$ & $0.001^{*}$ \\
\hline C16:0 & $26.91 \pm 2.83$ & $26.30 \pm 3.33$ & 0.411 \\
\hline C16:1 & $0.83 \pm 0.57$ & $0.59 \pm 0.24$ & $0.020^{*}$ \\
\hline C18:0 & $19.29 \pm 2.60$ & $19.78 \pm 2.97$ & 0.467 \\
\hline $\mathrm{C} 18: 1$ & $16.49 \pm 2.51$ & $15.62 \pm 2.29$ & 0.124 \\
\hline $\mathrm{C} 18: \ln 7 t$ & $0.11 \pm 0.035$ & $0.066 \pm 0.034$ & $0.000^{*}$ \\
\hline $\mathrm{C} 18: \ln 9 t$ & $0.33 \pm 0.17$ & $0.57 \pm 0.20$ & $0.000^{*}$ \\
\hline C18:2n6 & $14.27 \pm 1.55$ & $13.03 \pm 1.83$ & $0.003^{*}$ \\
\hline $\mathrm{C} 18: 2 \mathrm{n} 6 t$ & $0.59 \pm 0.55$ & $0.58 \pm 0.57$ & 0.968 \\
\hline $\mathrm{C} 18: 2 \mathrm{n} 7 t$ & $0.065 \pm 0.066$ & $0.16 \pm 0.14$ & $0.000^{*}$ \\
\hline $\mathrm{C} 18: 3 \mathrm{n} 3$ & $0.24 \pm 0.16$ & $0.22 \pm 0.086$ & 0.359 \\
\hline $\mathrm{C} 20: 4 \mathrm{n} 6$ & $13.80 \pm 3.66$ & $15.16 \pm 4.18$ & 0.148 \\
\hline C20:5n 3 & $0.39 \pm 0.14$ & $0.43 \pm 0.16$ & 0.329 \\
\hline $\mathrm{C} 22: 6 \mathrm{n}$ & $3.03 \pm 0.84$ & $3.06 \pm 1.16$ & 0.908 \\
\hline $\mathrm{C} 24: 1$ & $2.66 \pm 0.93$ & $3.75 \pm 1.21$ & $0.000^{*}$ \\
\hline$\Sigma$ Sat & $47.21 \pm 4.56$ & $46.74 \pm 5.57$ & 0.700 \\
\hline$\Sigma$ MUFA & $20.34 \pm 2.40$ & $19.96 \pm 1.86$ & 0.441 \\
\hline$\Sigma$ PUFA & $31.36 \pm 4.93$ & $31.88 \pm 6.19$ & 0.695 \\
\hline $\mathrm{n} 6 / \mathrm{n} 3$ & $9.16 \pm 2.46$ & $8.79 \pm 4.81$ & 0.698 \\
\hline Etrans & $1.09 \pm 0.61$ & $1.38 \pm 0.63$ & 0.051 \\
\hline
\end{tabular}

Data are expressed as mean $\pm \mathrm{SD}(\%$ of FA content $) .{ }^{*} \mathrm{P}<0.05$. 
(C18:1n7t), and linoleic acids (C18:2); and a higher one of elaidic (C18:1n9t), conjugated linoelaidic (C18:2n7t), and nervonic acids (C24:1) when compared to the Control Group; the sum of saturated, monounsaturated and polyunsaturated fats showed no significant difference between groups; however, the sum of total trans fat showed a marginal significant difference.

Although we did found a significant difference in conjugated linoelaidic acid's proportion between study groups, data didn't have a normal distribution even after a logarithmic transformation was performed. Moreover, this FA was present in erythrocytes' membranes just as traces and we weren't able to identify it in 23 study subjects (13 of the Control Group, and 10 of MS Group). Because of this, we decided to suppress this FA from all further analyses.

In order to build contingency tables, and to successfully analyze OR with the most accurate data; we pro- posed different cut-off points according to ROC curve analyses.

Each ROC curve was constructed using the FA's content in erythrocytes' membrane (expressed in \%) and the presence or absence of MS (dichotomous variable). We selected the cut-off points according to sensitivity and specificity values (Table 3). ROC curve analyses were performed only for the FAs that differed significantly amongst groups.

Table 4 resumes the ORs obtained from the contingency tables; by analyzing data on table 4 , we can realize that nervonic $(24: 1)$ and elaidic acids $(\mathrm{C} 18: \ln 9 t)$ had a strong positive association with MS; whereas myristic (C14), vaccenic $(\mathrm{C} 18: 1 \mathrm{n} 7 t)$, and linoleic acids (C18:2) appear to have a protective effect against the disease.

Finally, to determine association between those FAs that were different between groups and each component of the MS, we constructed a correlation matrix (Table 5).

Table 3. Determination of a cut-off point for selected FAs.

\begin{tabular}{cccccc}
\hline Fatty acid & Cut-off point (\%) & Sensitivity (\%) & Specificity (\%) & AUC & $P$ \\
\hline C14 & 0.62 & 77.3 & 67.7 & 0.75 & 0.000 \\
C16:1 & 0.55 & 50 & 54.8 & 0.55 & 0.42 \\
C18:1n9t & 0.39 & 81.8 & 74.2 & 0.81 & 0.000 \\
C18:1n7t & 0.085 & 75 & 71 & 0.83 & 0.000 \\
C18:2 & 13.9 & 68.2 & 67.7 & 0.71 & 0.002 \\
C24:1 & 3.31 & 77.3 & 77.4 & 0.81 & 0.000 \\
\hline
\end{tabular}

Table 4. Odds ratios $(95 \% \mathrm{CI})$ of selected FA against MS.

\begin{tabular}{cccccc}
\hline \multirow{2}{*}{ Fatty Acid } & \multicolumn{2}{c}{ Control Group } & \multicolumn{2}{c}{ MS Group } & $\begin{array}{c}\text { Odds Ratio } \\
(\text { CI }) 95 \%\end{array}$ \\
\cline { 2 - 5 } C14 & Exposed & Not Exposed & Exposed & Not Exposed & 0.14 \\
Cases (n) & $>0.62 \%$ & $<0.62 \%$ & $>0.62$ & $<0.62$ & $(0.05-0.39)$ \\
C16:1 & 21 & 10 & 10 & 34 & 0.82 \\
Cases (n) & $>0.55 \%$ & $<0.55 \%$ & $>0.55 \%$ & $<0.55 \%$ & $(0.33-2.05)$ \\
C18:1n7t & 17 & 14 & 22 & 22 & 0.14 \\
Cases (n) & 22 & $<0.085 \%$ & $>0.085 \%$ & $<0.085 \%$ & $(0.05-0.39)$ \\
C18:1n9t & $>0.35 \%$ & $985 \%$ & 11 & 33 & 12.94 \\
Cases (n) & 8 & 23 & $>0.35 \%$ & $<0.35 \%$ & $(4.26-39.25)$ \\
C18:2 & $>13.9 \%$ & $<13.9 \%$ & 36 & 8 & 0.22 \\
Cases (n) & 21 & 10 & $13.9 \%$ & $<13.9 \%$ & $(0.082-0.58)$ \\
C24:1 & $>3.31 \%$ & $<3.31 \%$ & $>3.31 \%$ & $<3.31 \%$ & 14.17 \\
Cases (n) & 6 & 25 & 34 & 10 & $(4.52-44.26)$ \\
\hline
\end{tabular}


Table 5. Correlation matrix between MS components and certain fas.

\begin{tabular}{ccccccc}
\hline & $\mathrm{WC}$ & $\mathrm{FG}$ & $\mathrm{TAG}$ & $\mathrm{HDL}$ & $\mathrm{SBP}$ & $\mathrm{DBP}$ \\
\hline $\mathrm{C} 14$ & $-0.32^{\diamond}$ & $-0.28^{*}$ & $-0.29^{*}$ & $0.38^{\bullet}$ & $-0.23^{*}$ & $\mathrm{NS}$ \\
$\mathrm{C} 16: 1$ & $\mathrm{NS}$ & $\mathrm{NS}$ & $\mathrm{NS}^{*}$ & $\mathrm{NS}$ & $\mathrm{NS}$ & $\mathrm{NS}$ \\
$\mathrm{C} 18: 1 \mathrm{ln} 7 t$ & $-0.488^{\bullet}$ & $-0.47^{\bullet}$ & $-0.49^{\bullet}$ & $0.39^{\bullet}$ & $-0.28^{*}$ & $-0.3^{\diamond}$ \\
$\mathrm{C} 18: 1 \mathrm{n} 9 t$ & $0.53^{\bullet}$ & $0.27^{*}$ & $0.35^{\diamond}$ & $-0.4^{\bullet}$ & $0.22^{*}$ & $0.34^{\diamond}$ \\
$\mathrm{C} 18: 2$ & $-0.35^{\diamond}$ & $\mathrm{NS}$ & $\mathrm{NS}$ & $\mathrm{NS}$ & $-0.39^{\bullet}$ & $-0.27^{*}$ \\
$\mathrm{C} 24: 1$ & $0.31^{\diamond}$ & $\mathrm{NS}$ & $0.39^{\bullet}$ & $-0.31^{\diamond}$ & $\mathrm{NS}$ & $\mathrm{NS}$ \\
\hline
\end{tabular}

$\mathrm{WC}=$ Waist Circumference; FG = Fasting Glucose TAG = Triglycerides; HDL = High Density Lipoprotein; SBP = Systolic Blood Pressure; DBP $=$ Diastolic Blood Pressure. ${ }^{*} \mathrm{P}<0.05 ;{ }^{\circ} \mathrm{P}<0.01 ;{ }^{\circ} \mathrm{P}<0.001$. NS $=$ No significance reported.

A positive association was observed against $24: 1$ and $\mathrm{C} 18: \ln 9 t$ and most of the MS components. In contrast, $\mathrm{C} 18: 2, \mathrm{C} 18: \ln 7 t, \mathrm{C} 14$ showed and inverse association.

\section{Discussion}

Our results demonstrate that the proportion of certain FAs in erythrocytes' membranes differs between adolescents with MS and healthy controls. By analyzing the ORs obtained, we can infer that $\mathrm{C} 24: 1$ and $\mathrm{C} 18: \ln 9 t$ play a role in the development of MS; whereas C14, C18:1n7t, and $\mathrm{C} 18: 2$ apparently provide a protective effect against the disease.

When we analyzed the correlation coefficients between each FA and each component of the MS, we realized that the FAs with the highest ORs, also have the strongest associations; for instance $\mathrm{C} 18: \ln 9 t(\mathrm{OR}=$ 12.94) correlated positively with all of the components of the MS, particularly with $\mathrm{WC}(\mathrm{r}=0.53, \mathrm{P}<0.01)$; and $\mathrm{C} 24: 1(\mathrm{OR}=14.17)$ showed a fair association with $\mathrm{TG}(\mathrm{r}$ $=0.39, \mathrm{P}<0.01)$. The same behavior was observed with the protective FAs, we can appreciate that the FAs with the lowest ORs have the strongest correlations; for example $\mathrm{C} 18: \ln 7 t(\mathrm{OR}=0.14)$ correlated inversely with all of the components of the MS, predominantly with FG, $\mathrm{TG}$, and $\mathrm{WC}(0.47,0.48,0.49$, respectively, $\mathrm{P}<0.01)$; and $\mathrm{C} 14(\mathrm{OR}=0.14)$ showed a moderate correlation with most of the Syndrome's components.

Since there is no information available about what kind of FA profile to expect in a healthy child, in order to provide ORs we needed to suggest a cut-off point for each FA's concentration. We can assume that selecting a cut-off point obtained from a ROC curve to analyze OR is a valid approach, this is supported by the high sensitivity, specificity, and area under the curve that we found and thus suggests that selected FAs could be useful as MS biomarkers.

As we previously mentioned, elaidic $(\mathrm{C} 18: \ln 9 t)$ and linoelaidic acids $(\mathrm{C} 18: 2 \mathrm{n} 7 t)$ are trans fats, formed in the food industry during the partial hydrogenation of vegetable oils; when analyzing the quality and quantity of the fat present in the Mexican diet, Villalpando et al found a high content of this two TFAs in a variety of fast foods, margarines, crackers, fries, and doughnuts widely commercialized in Mexico ( $>2 \% \mathrm{~g} / 100 \mathrm{~g}$ ) [32]; as we now know, the consumption of industrial TFAs is associated with weight gain and visceral fat accumulation in male adult subjects [33] and it may also increase LDL-C and TG and reduce HDL-C [17]. Although no differences were found in linoelaidic acid $(\mathrm{C} 18: 2 \mathrm{n} 6 t)$ concentration between study groups, MS Group had a higher concentration of elaidic acid $(\mathrm{C} 18: \ln 9 t)$, and this $t \mathrm{FA}$ also showed an important association with MS $(\mathrm{OR}=12.94)$.

On the other hand, vaccenic and conjugated linolenic acids are TFAs from ruminants that are present in smaller amounts in dairy products and meat; current evidence suggests that TFAs from ruminants have limited implications against health [20]. Our results are consistent with previously reported data; and we did found a negative association between vaccenic acid $(\mathrm{C} 18: 1 \mathrm{n} 7 t)$ and all of the components of MS. Interestingly, the sum of TFAs $(\mathrm{C} 18: \ln 7 t, \mathrm{C} 18: 1 \mathrm{n} 9 t, \mathrm{C} 18: 2 \mathrm{n} 6 t$, and $\mathrm{C} 18: 2 \mathrm{n} 7 t)$ had an OR of 4.71 (CI 95\%: 1.73 - 12.8) but no association was found with MS or its components; so it seems that analyzing each TFA separately instead of considering the total sum is a better approach.

When we analyzed the data obtained, we realized that nervonic acid (C24:1) had the highest association with MS $(\mathrm{OR}=14.17)$, however, to our knowledge, there aren't any previously reported studies that involve this FA with MS. Straczkowski et al found that skeletal muscle ceramides have an important proportion of C24:1 $(5.8 \%)$ and that this proportion correlates inversely with insulin sensitivity $(\mathrm{r}=-0.39, \mathrm{P}=0.047$ vs clamp) [34]. Ceramide is the main second messenger derived from the hydrolysis of membrane sphingomyelin and is directly involved in cell differentiation, inhibition of cell proliferation, induction of apoptosis, and more recently with 
glucose uptake stimulated by insulin action [35]; probably, the higher amount of C24:1 found in the erythrocytes' membranes of our study subjects with MS, is closely related with an insulin resistance state.

Although MS Group has a detrimental metabolic condition it is noteworthy that no differences were found in linolenic acid (C18:3n3), eicosapentaenoic acid (C20: $5 \mathrm{n} 3)$, docosahexaenoic acid (C22:6n3), sum of PUFAs, or $n-6 / n-3$ ratio when compared to the Control Group. Since the beneficial role of n-3 family in lipid metabolism is well known, we expected to find a lower proportion of these FAs in the MS Group. Despite there is evidence that supports the fact that the Mexican diet is insufficient in n-3 and in n-6 in nearly the 52\% of Mexican adolescents [29]; when we analyzed the proportion of C18:3n3, C20:4n6, C20:5n3, C22:6n3, EPUFAs, and $\mathrm{n}-6 / \mathrm{n}-3$ ratio, in both groups (75 subjects) we found that Mexican children and adolescents have a similar FA profile to the one previously reported in comparable populations of Hungarian and Australian children [36,37]. These results suggest that there is an increased n-3 synthesis in Mexican Adolescents that successfully compensates the insufficient dietary intake.

Description of the FA profile in erythrocytes' membranes of the Control Group is an important contribution of the present study, since there isn't enough data about the FA profile in healthy young populations; we dare to suggest that the described profile in lean adolescents may be used as reference data for further studies.

In summary, the proportion of specific FAs in erythrocytes' membranes differs between adolescents with MS and healthy controls; these FA not only showed a strong association with MS, but also correlated with most of its individual components. Additionally TFAs displayed an antagonic behavior; these results suggest that analyzing each TFA separately will constitute a more accurate approach to determine the role of TFAs in the pathogenesis of MS or other related metabolic disorders.

\section{REFERENCES}

[1] E. D'Adamo, N. Santoro and S. Caprio, "Metabolic Syndrome in Pediatrics: Old Concepts Revised, New Concepts Discussed," Current Problems Pediatrics Adolescents Health Care, Vol. 43, No. 5, 2013, pp.114-123. doi:10.1016/j.cppeds.2013.02.004

[2] P. Zimmet, K. G. Alberti, F. Kaufman, N. Tajima, M. Silink, S. Arslanian, et al., "The Metabolic Syndrome in Children and Adolescents-An IDF Consensus Report," Pediatric Diabetes, Vol. 8, No. 5, 2007, pp. 299-306.

[3] D. S. Ludwig, "Childhood Obesity-The Shape of Things to Come," The New England Journal of Medicine, Vol. 357, No. 23, 2009, pp. 2329-2371.
[4] R. Weiss, J. Dziura, T. S. Burgert, W. V. Tamborlane, S. E. Taksali, C. W. Yeckel, et al., "Obesity and the Metabolic Syndrome in Children and Adolescents," The New England Journal of Medicine, Vol. 350, No. 23, pp. 2362-2374. doi:10.1056/NEJMoa031049

[5] G. N. A. Thankamony, R. Williams and D. B. Dunger, "Metabolic Syndrome in Children Unravelled," Paediatrics and Child Health, Vol. 21, No. 7, 2011, pp. 21-27. doi:10.1016/j.paed.2011.03.010

[6] A. P. Simopoulos, "The Importance of the Ratio of Omega-6/Omega-3 Essential Fatty Acids," Biomedical Pharmacotherapy, Vol. 56, No. 8, 2002, pp. 365-379. doi:10.1016/S0753-3322(02)00253-6

[7] U. Risérus, "Fatty Acids and Insulin Sensitivity," Current Opinion in Clinical Nutrition and Metabolic Care, Vol. 11, No. 2, 2008, pp. 100-105. doi:10.1097/MCO.0b013e3282f52708

[8] L. Arab, "Biomarkers of Fat and Fatty Acid Intake," The Journal of Nutrition, Vol. 133, No. 3, 2003, pp. 925S932S.

[9] S. D. Poppitt, P. Kilmartin, P. Butler and G. F. Keogh, "Assessment of Erythrocyte Phospholipid Fatty Acid Composition as a Biomarker for Dietary MUFA, PUFA or Saturated Fatty Acid Intake in a Controlled Cross-Over Intervention Trial," Lipids in Health and Disease, Vol. 4, No. 30, 2005, pp. 30-39.

[10] H. D. Orton, N. J. Szabo, M. Clare-Salzler and J. M. Norris, "Comparison between Omega-3 and Omega-6 Polyunsaturated Fatty Acid Intakes as Assessed by a Food Frequency Questionnaire and Erythrocyte Membrane Fatty Acid Composition in Young Children," European Journal of Clinical Nutrition, Vol. 62, 2008, pp. 733-738. doi:10.1038/sj.ejcn.1602763

[11] E. Warensjö, J. Sundström, L. Lind and B. Vessby, "Factor Analysis of Fatty Acids in Serum Lipids as a Measure of Dietary Fat Quality in Relation to the Metabolic Syndrome in Men," The American Journal of Clinical Nutrition, Vol. 84, No. 2, 2006, pp. 442-448.

[12] P. Risé, S. Eligini, S. Ghezzi, S. Colli and C. Galli, "Fatty Acid Composition of Plasma, Blood Cells and Whole Blood: Relevance for the Assessment of the Fatty Acid Status in Humans," Prostaglandins, Leukotrienes and Essential Fatty Acids, Vol. 76, No. 6, 2007, pp. 363-369. doi:10.1016/j.plefa.2007.05.003

[13] L. A. Baur, J. O'Connor, D. A. Pan, A. D. Kriketos and L. H. Storlien, "The Fatty Acid Composition of Skeletal Muscle Membrane Phospholipid: Its Relationship with the Type of Feeding and Plasma Glucose Levels in Young Children," Metabolism, Vol. 47, No. 1, 1998, pp. 106-112. doi:10.1016/S0026-0495(98)90202-5

[14] T. P. Novgorodtseva, Y. K. Karaman, N. V. Zhukova, E. G. Lobanova, M. V. Antonyuk and T. A. Kantur, "Composition of Fatty Acids in Plasma and Erythrocytes and Eicosanoids Level in Patients with Metabolic Syndrome," Lipids in Health and Disease, Vol. 10, No. 82, 2011, pp. 82-86.

[15] E. K. Kabagambe, M. Y. Tsai, P. N. Hopkins, J. M. Or- 
dovas, J. M. Peacock, I. B. Borecki, et al., "Erythrocyte Fatty Acid Composition and the Metabolic Syndrome: A National Heart, Lung, and Blood Institute GOLDN Study," Clinical Chemistry, Vol. 54, No. 1, 2007, pp. 154-162. doi:10.1373/clinchem.2007.095059

[16] P. Mirmiran, S. Hosseinpour-Niazi, Z. Naderi, Z. Bahadoran, M. Sadeghi, F. Azizi, "Association between Interaction and Ratio of $\omega-3$ and $\omega-6$ Polyunsaturated Fatty Acid and the Metabolic Syndrome in Adults," Nutrition, Vol. 28, No. 9, 2012, pp. 856-863. doi:10.1016/j.nut.2011.11.031

[17] D. Mozaffarian, "Trans Fatty Acids-Effects on Systemic Inflammation and Endothelial Function," Atherosclerosis Supplements, Vol. 7, No. 2, 2006, pp. 29-32. doi:10.1016/j.atherosclerosissup.2006.04.007

[18] E. Christiansen, S. Schnider, B. Palmvig, E. TauberLassen and O. Pedersen, "Intake of a Diet High in Trans Monounsaturated Fatty Acids or Saturated Fatty Acids. Effects on Postpandrial Insulinemia and Glycemia in Obese Patients with NIDDM," Diabetes Care, Vol. 20, No. 5, 1997, pp. 881-887. doi:10.2337/diacare.20.5.881

[19] U. Risérus, P. Arner, K. Brismar and B. Vessby, "Treatment with Dietary Trans 10 cis 12 Conjugated Linoleic Acid Causes Isomer-Specific Insulin Resistance in Obese Men with the Metabolic Syndrome," Diabetes Care, Vol. 25, No. 9, 2002, pp. 1516-1521. doi:10.2337/diacare.25.9.1516

[20] D. Mozaffarian, M. B. Katan, A. Ascherio, M. J. Stampfer and W. C. Willett, "Trans Fatty Acids and Cardiovascular Disease," The New England Journal of Medicine, Vol. 354, 2006, pp. 1601-1613. doi:10.1056/NEJMra054035

[21] R. Micha and D. Mozaffarian, "Trans Fatty Acids: Effects on Cardiometabolic Health and Implications for Policy," Prostaglandins, Leukotrienes and Essential Fatty Acids, Vol. 79, 2008, pp. 147-152. doi:10.1016/j.plefa.2008.09.008

[22] J. Fritsche and H. Steinhart, "Analysis, Occurrence, and Physiological Properties of Trans Fatty Acids (TFA) with Particular Emphasis on Conjugated Linoleic Acid Isomers (CLA)-A Review," European Journal of Lipid Science and Technology, Vol. 100, No. 6, 1998, pp. 190210.

[23] P. Salo, T. Seppänen-Laakso, I. Laakso, R. Seppänen, H. Niinikoski, J. Viikari and O. Simell, "Low Saturated Fat, Low-Cholesterol Diet in 5-Year-Old Children: Effect on Intake and Composition of Trans Fatty Acids and Other Fatty Acids in Serum Phospholipid Fraction-The STRIP Study," The Journal of Pediatrics, Vol. 136, No. 1, 2000, pp. 46-52. doi:10.1016/S0022-3476(00)90048-9

[24] J. E. Hunter, "Dietary Levels of Trans-Fatty Acids: Basis for Health Concerns and Industry Efforts to Limit Use," Nutrition Research, Vol. 25, No. 5, 2005, pp. 499-513. doi:10.1016/i.nutres.2005.04.002

[25] A. H. Lichtenstein, "Trans Fatty Acids and Blood Lipid Levels, Lp(A), Parameters of Cholesterol Metabolism, and Hemostatic Factors," The Journal of Nutritional
Biochemistry, Vol. 9, No. 9, 1998, pp. 244-248. doi:10.1016/S0955-2863(98)00016-3

[26] F. Shahidi and S. P. J. N. Senanayake, "Fatty Acids," In: K. Heggenhougen, Ed., International Encyclopedia of Public Health, Academic Press, San Diego, pp. 594-603.

[27] R. P. Mensink and M. B. Katan. "Effect of Dietary Trans Fatty Acids on High-Density and Low-Density Lipoprotein Cholesterol Levels in Healthy Subjects," The New England Journal of Medicine, Vol. 323, 1990, pp. 439-445. doi:10.1056/NEJM199008163230703

[28] J. T. Judd, B. A. Clevidence, R. A. Muesing, J. Wittes, M. E. Sunkin and J. J. Podczasy, "Dietary Trans-Fatty Acids: Effects on Plasma Lipids and Lipoproteins of Healthy Men And Women," The American Journal of Clinical Nutrition, Vol. 59, 1994, pp. 861-868.

[29] I. Ramírez-Silva, S. Villalpando, J. E. Moreno-Saracho and D. Bernal-Medina, "Fatty Acids Intake in the Mexican Population. Results of the National Nutrition Survey 2006," Nutrition \& Metabolism, Vol. 8, No. 33, 2011.

[30] J. R. Fernández, D. T. Redden, A. Petrobelli and D. B. Allison, "Waist Circumference Percentiles in Nationally Representative Samples of African-American, EuropeanAmerican, and Mexican-American Children and Adolescents," The Journal of Pediatrics, Vol. 145, 2004, pp. 439-444. doi:10.1016/j.jpeds.2004.06.044

[31] National High Blood Pressure Education Program Working Group on High Blood Pressure in Children and Adolescents, "The Fourth Report on the Diagnosis, Evaluation, and Treatment of High Blood Pressure in Children and Adolescents," Pediatrics, Vol. 114, No. 2, 2004, pp. 555-576. doi:10.1542/peds.114.2.S2.555

[32] S. Villalpando, I. Ramírez-Silva, D. Bernal-Medina and V. De la Cruz-Góngora, "Grasas, Dieta y Salud: Tablas de Composición de Ácidos Grados de Alimentos Frecuentes en la Dieta Mexicana," Instituto Nacional de Salud Pública, México City, 2007.

[33] P. Koh-Banerjee, N. F. Chu, D. Spiegelman, B. Rosner, G. Colditz, W. Willet, et al., "Prospective Study of the Association of Changes in Dietary Intake, Physical Activity, Alcohol Consumption, and Smoking with 9-y Gain in Waist Circumference Among 16587 US Men," The American Journal of Clinical Nutrition, Vol. 78, 2003, pp. 719-727.

[34] M. Straczkowski, I. Kowalska, A. Nikolajuk, S. DzienisStraczkowska, I. Kinalska, M. Baranowski, et al., "Relationship between Insulin Sensitivity and Sphingomyelin Signaling Pathway in Human Skeletal Muscle," Diabetes, Vol. 53, 2004, pp. 1215-1221. doi:10.2337/diabetes.53.5.1215

[35] J. Górski, A. Dobrzyn and M. Zendzian-Piotrowska, "The Sphingomyelin-Signalig Pathway in Skeetal Muscles and Its Role in Regulation of Glucose Uptake," Annals of the New York Academy of Sciences, Vol. 967, 2002, pp. 236-248. doi:10.1111/j.1749-6632.2002.tb04279.x

[36] V. Jakobik, I. Burus and T. Decsi, "Fatty Acid Composition of Erythrocyte Membrane Lipids in Healthy Subjects from Birth to Young Adulthood," European Journal of Pediatrics, Vol. 168, 2009, pp. 141-147. 
doi:10.1007/s00431-008-0719-9

[37] T. Burrows, C. E. Collins and M. L. Garg, "Omega-3 Index, Obesity and Insulin Resistance in Children," In- ternational Journal of Pediatric Obesity, Vol. 6, 2011, pp. e532-e539. doi:10.3109/17477166.2010.549489. 